\title{
Effect of supplementation of probiotics and phytosterols alone or in combination on serum and hepatic lipid profiles and thyroid hormones of hypercholesterolemic rats
}

\author{
S. S. Awaisheh, ${ }^{* 1}$ M. S. Khalifeh, $†$ M. A. Al-Ruwaili, $¥$ O. M. Khalil, $¥$ O. H. Al-Ameri, $†$ and R. Al-Groom§ \\ *Department of Food Science, Al-Balqa Applied University, 19117, Salt, Jordan \\ †Department of Veterinary Basic Sciences, Jordan University of Science and Technology, 22110, Irbid, Jordan \\ $\ddagger$ College of Applied Medical Science, Al-Jouf University, Al-Jouf 2014, Saudi Arabia \\ $\S$ Department of Food Science, Al-Balqa Applied University, 19237, Zarqa, Jordan
}

\section{ABSTRACT}

Probiotic bacteria and phytosterols are natural hypocholesterolemic agents with potential cardiovascular benefits. Accordingly, the present study was conducted to evaluate the effect of supplementation of probiotics and phytosterols alone or in combination on serum and hepatic lipid profiles and thyroid hormones of hypercholesterolemic rats. Mixed probiotics treatment consisted of 8 probiotic strains: 2 strains of each of Lactobacillus acidophilus, Lactobacillus casei, Lactobacillus gasseri, and Lactobacillus reuteri. The rats were fed for $8 \mathrm{wk}$ with the given treatments in addition to a high-fat-high-cholesterol basal diet to induce hypercholesterolemia. Results showed that supplementation significantly reduced serum total cholesterol, lowdensity-lipoprotein cholesterol (LDL-C), high-densitylipoprotein cholesterol, and triglycerides compared with the controls. The symbiotic treatment was more effective in lowering LDL-C, whereas mixed probiotics treatment more effectively lowered serum total cholesterol and LDL-C than the phytosterol-containing treatment. The phytosterol-containing treatments induced the increased activity of thyroid glands, as evident by elevated levels of serum total thyroxine, total triiodothyronine, and free triiodothyronine. In conclusion, the lipid profile can effectively be reduced to lower the incidence of cardiovascular disease using combinations of Lactobacillus-based probiotics and phytosterols in functional foods.

Key words: mixed probiotics, symbiotic phytosterol, hypocholesterolemic, thyroid hormone

\section{INTRODUCTION}

Cardiovascular disease (CVD) is the leading cause of mortality and morbidity in the world. Atherosclerosis is

\footnotetext{
Received February 16, 2012.

Accepted October 11, 2012.

${ }^{1}$ Corresponding author: saddam_awaisheh@yahoo.com
}

the underlying pathology of CVD. Elevated total cholesterol (TC) and low-density-lipoprotein cholesterol (LDL-C), and low high-density-lipoprotein cholesterol (HDL-C) are among the major contributors to atherosclerosis and CVD (WHO, 2007). Several classes of cholesterol-lowering drugs are available. Use of these drugs has been limited due to the high incidence of side effects, which include gastrointestinal distress, fatigue, increase in liver enzymes, liver damage, severe flushing, and high cost (Talbert, 2006; Kiortsis et al., 2007).

As a result of these factors, functional foods as dietary approaches to lower cholesterol and, consequently, CVD risks are increasingly found to be more appealing over drug alternatives. Probiotics and phytosterols are generally considered among important hypocholesterolemic functional candidates. Probiotics are selected viable microorganisms used as dietary supplements for their potential benefits for human health or disease prevention (Schrezenmeir and de Vrese, 2001). Hypocholesterolemic effects of Lactobacillus species have been reported, including Lactobacillus acidophilus (Sibel Akalin et al., 1997; Chien et al., 2010), Lactobacillus casei (Brashears et al., 1998; Liong and Shah, 2006), Lactobacillus gasseri (Usman and Hosono, 2000), and Lactobacillus reuteri (Taranto et al., 2000). Phytosterols (naturally occurring sterols of plant origin) have been found to lower serum cholesterol by inhibiting cholesterol absorption from the intestine (Moghadasian and Frohlich, 1999; Ntanios and Jones, 1999). Piironen et al. (2000) concluded from surveying several studies that the consumption of phytosterol esters $(2 \mathrm{~g} / \mathrm{d})$ can reduce LDL-C cholesterol by 10 to $15 \%$.

It is well established that hyperthyroidism reduces serum levels of TC and LDL-C due to the increased expression of LDL-C receptor and, consequently, enhanced LDL-C clearance from serum (Shin and Osborne, 2003; Lagor and Millar, 2010). However, the effect of probiotics and phytosterols on modulating thyroid hormones (TH) has been scarcely investigated. Panda et al. (2009) reported that soy sterols 
(containing sitosterol, stigmasterol, and campesterol), at a moderate concentration $(5 \mathrm{mg} / \mathrm{kg})$ significantly increased serum thyroxine (T4) and reduced triiodothyronine (T3), but at a higher concentration $(10 \mathrm{mg} /$ $\mathrm{kg}$ ), it exerted adverse effects. For probiotics, only one study investigated and reported the lack of this effect (Ali et al., 2004). Moreover, very limited number of studies investigated the symbiotic effect of probiotics and phytosterols on serum TC and LDL-C (Mannarino et al., 2009; Chien et al., 2010).

Recently, new trends in developing multi-beneficial symbiotic products has emerged by incorporating mixed probiotic strains with more than one functional agent to maximize the health effects of functional foods (Abd El-Salam et al., 2011; Awaisheh, 2011). Probiotics and phytosterols possess different hypocholesterolemic mechanisms. Thus, investigating the symbiotic effect of probiotics and phytosterols to maximize the hypocholesterolemic effect and to investigate their modulating effect on $\mathrm{TH}$ as a possible tool to lower cholesterol has become a priority. Therefore, the present study aimed at evaluating the effect of supplementation of probiotics and phytosterols alone or in combination on serum and hepatic lipid profiles and thyroid hormones in hypercholesterolemic rats.

\section{MATERIALS AND METHODS}

\section{Probiotic Strains Source and Maintenance}

A total of 8 probiotic strains: 2 strains of each of $L b$. acidophilus (LA101; LA104); Lb. casei (LC202; LC207); Lb. gasseri (LG301; LG306); and Lb. reuteri (LR402; LR409), from the culture collection of the Department of Nutrition and Food Technology, Al-Balqa Applied University (Salt, Jordan), were used in this study (Awaisheh et al., 2012). These bacterial strains were previously shown to have promising probiotic characteristics, which include high acid and bile resistance, good adhesion properties, and antibacterial, antioxidative, and strong in vitro hypocholesterolemic activities (Awaisheh et al., 2005; Awaisheh, 2011). These strains were previously isolated from healthy, breast-fed, newborn Jordanian infants. To avoid any inhibition effect among the probiotic strains during fermented milk preparation and storage, the interactions among probiotic strains used in this study were evaluated in a previous study (Awaisheh et al., 2012). The strains were selected according to their lack or very weak inhibition effects. All the probiotic strains were maintained by subculture of $2 \%$ inoculum into prereduced de Man, Rogosa, and Sharpe (MRS) broth (R-MRS; MRS broth $+0.5 \%$ cysteine-HCl; Oxoid Ltd., Basingstoke, $\mathrm{UK})$ at $37^{\circ} \mathrm{C} / 18 \mathrm{~h}$ and kept at $4^{\circ} \mathrm{C}$ between transfers.

\section{Preparation of Nonfermented and Probiotic-Fermented Milk Treatments}

Four types of milk treatments were used in this study, namely, nonfermented milk (NFM), phytosterol-NFM (PNFM), probiotic-fermented milk (PFM), and phytosterol-probiotic-fermented milk (PPFM). For the production of all milk treatments, sterile skim milk (SSM) was prepared from dry skim milk base (90 $\mathrm{g}$ of milk solids/L milk; Regilait, Burgundy, France), sterilized at $121^{\circ} \mathrm{C}$ for $15 \mathrm{~min}$, and cooled to room temperature. Sterile skim milk was used as NFM. The PNFM was prepared by adding the phytosterol mixture $(\beta$-sitosterol + plant sterols; $5 \mathrm{mg} / \mathrm{mL})$ into milk before sterilization. The phytosterol mixture contained $50 \% \beta$-sitosterol, $25 \%$ campesterol, $20 \%$ stigmasterols, and $5 \%$ other sterols. The PFM and the PPFM were prepared by inoculating $10 \%$ of fresh mixed probiotic strains into SSM for the PFM, and to SSM with phytosterols for the PPFM, to achieve initial probiotics count of $108 \mathrm{cfu} / \mathrm{mL}$, which were then incubated anaerobically at $37^{\circ} \mathrm{C} / 18 \mathrm{~h}$. Mixed probiotic strains were prepared by combining $12.5 \%$ ( $\mathrm{vol} / \mathrm{vol}$ ) of each strain that was previously subcultured twice in SSM. Therefore, to prepare $1 \mathrm{~L}$ of mixed probiotics, $125 \mathrm{~mL}$ of each strain was combined. Based on the results of a previous study (Awaisheh et al., 2012), fermented milk can be prepared weekly and stored at $4^{\circ} \mathrm{C}$ for use during the week.

\section{Experimental Animals and Treatments}

Sixty rats (male Sprague-Dawley), 5 to 6 wk of age, were obtained from the Animal House, Jordan University of Science and Technology (Irbid, Jordan). Treatments and animal maintenance were in accordance with the guidelines of Jordan University of Science and Technology Animal Care and Use Committee, which follows the international animal care and use guidelines (ILAR, 1996). The rats were fed a rodent chow for 2 wk. Food and water were provided ad libitum. After this adaptation period, the rats were randomly divided into 5 groups of 12 rats each and each group was caged in a separate cage and fed a semi-purified diet based on the American Institute of Nutrition (AIN)-93 rodent diet (Table 1; Reeves et al., 1993). The first group (negative control, $\mathbf{C O N}-$ ) received a rodent chow diet, and the other 4 groups received high-fat-highcholesterol (HFHC) rodent chow diet. The HFHC diet contained $1 \%$ cholesterol, $10 \%$ butter fat, $0.3 \%$ sodium cholate, and $88.7 \%$ AIN-93-based diet (Table 1). Total fat contents were 15 and $5 \%$ for HFHC groups and CON - group, respectively. Then, the 4 HFHC groups received one of the following treatments: the NFM 
(positive control, CON+), PNFM, PFM, or PPFM. To ensure the exact and uniform receiving of the probiotic and phytosterol quantities by all animals, all the milk treatments were administered orally by gavage in 5 -mL doses, with $10^{10-11} \mathrm{cfu}$ of probiotic cells and 25 mg of phytosterols/d per rat. All the treatments were given once daily between 0800 and 0900 h. Food and liquid were accessible for animals at all times and were replaced daily. During the experiment, environmental conditions were controlled as follows; relative humidity was 55 to $60 \%$ and room temperature was $22 \pm 2{ }^{\circ} \mathrm{C}$, with 12-h light exposure (daily cycle from 0700 to 1900 h). The animals were fasted overnight and underwent further tests.

\section{Serum Lipid Profile Analysis}

The animals were euthanized using a carbon dioxide inhalation chamber method (Danneman et al., 1997). Blood samples of 12 rats of each group were taken from the cardiac aorta of anesthetized animals and transferred to nonheparinized vacuum blood collection tubes. The tubes were held stationary until the blood separated into 2 layers. Blood serum layers were centrifuged $\left(365 \times g\right.$ for $10 \mathrm{~min}$ at $\left.4^{\circ} \mathrm{C}\right)$ out for blood lipids analysis. The TC (cholesterol oxidase/peroxidase; code 11505; Chemelex SA, Canovelles, Spain), HDL-C (phosphotungstate/Mg-cholesterol oxidase/peroxidase; code 11523; Chemelex SA), and triglycerides (TG; TGGPO-POD, code 30363; Chemelex SA) were measured enzymatically using a spectrophotometer (Thermo Electron Scientific Co., Madison, WI). All the kits were obtained from Biosystems (Madrid, Spain). The LDL$\mathrm{C}$ was calculated by subtracting HDL-C from TC (Ali et al., 2004).

\section{Hepatic TG and TC Analysis}

The hepatic TC and TG were measured by a method as described by Folch et al. (1957). Briefly, after animals were euthanized, the viscera were opened and the liver was excised, washed with saline, dried with filter paper, and weighed. A $0.2-\mathrm{g}$ piece of liver tissue was placed in a sample bottle, to which 20 times the tissue volume (4 $\mathrm{mL}$ ) of Folch solution (chloroform:methanol = 2:1; vol/ vol) was added. Liver tissue was then homogenized and agitated for $30 \mathrm{~min}$ in an orbital shaker at room temperature to facilitate lipid extraction. The homogenate was then filtered with Whatman No. 2 filter paper, and quantified to $5 \mathrm{~mL}$. One hundred microliters of liver extractant in Folch solution was added to $5 \mu \mathrm{L}$ of Triton X-100 surfactant and dried under nitrogen. Hepatic

Table 1. Composition of the diets and treatments fed to the animal groups

\begin{tabular}{|c|c|c|c|c|c|}
\hline \multirow[b]{2}{*}{ Item } & \multirow[b]{2}{*}{ Control- ${ }^{1}$} & \multicolumn{4}{|c|}{ High-fat-high-cholesterol group $(\mathrm{HFHC})^{2}$} \\
\hline & & Control+ & PFM & PNFM & PPFM \\
\hline \multicolumn{6}{|l|}{ Ingredient (\%) } \\
\hline Basal chow diet & 100 & 88.7 & 88.7 & 88.7 & 88.7 \\
\hline Butter fat & - & 10 & 10 & 10 & 10 \\
\hline Cholesterol & - & 1 & 1 & 1 & 1 \\
\hline Sodium cholate & - & 0.3 & 0.3 & 0.3 & 0.3 \\
\hline \multicolumn{6}{|l|}{ Treatment } \\
\hline Probiotics (mL) & - & - & 5 & - & 5 \\
\hline Phytosterols (mg/mL) & - & - & - & 5 & 5 \\
\hline \multicolumn{6}{|l|}{ Basal chow diet $(\mathrm{g} / \mathrm{kg})$} \\
\hline Soy protein & 305.4 & & & & \\
\hline Cornstarch & 546.9 & & & & \\
\hline Cellulose & 50 & & & & \\
\hline Soybean oil & 50 & & & & \\
\hline AIN-93 mineral $\operatorname{mix}^{3}$ & 35 & & & & \\
\hline AIN-93 vitamin $\operatorname{mix}^{4}$ & 10 & & & & \\
\hline Choline bitartrate & 2.5 & & & & \\
\hline$t$-Butylhydroquinone & 0.20 & & & & \\
\hline
\end{tabular}

${ }^{1}$ Control - = group fed rodent chow.

${ }^{2}$ Control+ $=$ group fed the HFHC diet and sterile skim milk (SSM); PFM = group fed probiotic-fermented milk; PNFM = group fed phytosterol-nonfermented milk; PPFM = group fed phytosterol-probiotic-fermented milk (10 $10^{11} \mathrm{cfu}$ of probiotics and $25 \mathrm{mg}$ of phytosterols/rat per day).

${ }^{3} \mathrm{AIN}=$ American Institute of Nutrition. Mineral mix contained (mg/kg of diet) Ca, 5,000; P, 1,992; K, 3,600; S, 300; Na, 1,019; Cl, 1,571; Mg, 507; Fe, 35; Zn, 30; Mn, 10; Cu, 6; I, 0.2; Mo, 0.15; Se, 0.15(Reeves et al., 1993).

${ }^{4}$ Vitamin mix contained (per kg of diet) nicotinic acid, $30 \mathrm{mg}$; pantothenate, $15 \mathrm{mg}$; pyridoxine, $6 \mathrm{mg}$; thiamin, $5 \mathrm{mg}$; riboflavin, $6 \mathrm{mg}$; folic acid, $2 \mathrm{mg}$; vitamin $\mathrm{K}$, $750 \mu \mathrm{g}$; D-biotin, $200 \mu \mathrm{g}$; vitamin $\mathrm{B}_{12}, 25 \mu \mathrm{g}$; vitamin A, 4,000 IU; vitamin $\mathrm{D}_{3}, 1,000 \mathrm{IU}$; and vitamin E, 75 IU (Reeves et al., 1993). 
TC and TG were analyzed as mentioned above, results expressed as $\mathrm{mg} / \mathrm{g}$ liver.

\section{Serum Thyroid (Free and Total T3 and T4) and Thyroid-Stimulating Hormone Analysis}

Serum levels of total and free T3 and T4, and thyroidstimulating hormones (TSH) were determined using enzyme immunoassay methods using a BioTek ELX800 ELISA reader (BioTek Instruments Inc., Winooski, VT). For total and free T3 and T4 hormones, competitive ELISA kits were used (codes 125-300, 1325-300, 225-300, and 1225-300). For TSH hormones, an immunoenzymometric assay kit was used (code 325-300). All kits (AccuBind) were obtained from Monobind Inc. (Lake Forest, CA).

\section{Statistical Analysis}

All data were analyzed using one-way ANOVA of the SAS software version 9.3 (SAS Institute, 2011). A least significant difference (LSD) test was performed to compare any significant differences $(P<0.05$, unless otherwise indicated) in variables between groups. The data normal distribution was analyzed using the PROC UNIVARIATE of SAS.

\section{RESULTS AND DISCUSSION}

\section{Serum Lipid Profiles}

The serum levels of TC, HDL-C, LDL-C, and TG of rats supplemented with a cocktail of probiotics and phytosterols alone or combined are shown in Table 2. The HFHC diet fed to the CON+ group significantly $(P<0.01)$ raised serum TC, LDL-C, HDL-C, and TG levels to $170.5,83.2,85.1$, and $110.8 \mathrm{mg} / \mathrm{dL}$, respectively. In comparison with the $\mathrm{CON}+$ group, all the fed treatments (PFM, PNFM, and PPFM) significantly $(P<0.01)$ lowered TC, LDL-C, HDL-C, and TG. The PFM treatment lowered the serum TC, LDL-C, HDLC, and TG levels to 109.5, 57.1, 48.6, and $79.2 \mathrm{mg} /$ $\mathrm{dL}$, respectively, whereas the PNFM treatment lowered serum TC, HDL-C, LDL-C, and TG levels to 133.6, $62.3,68.2$, and $93.4 \mathrm{mg} / \mathrm{dL}$, respectively; the PPFM treatment lowered serum TC, HDL-C, LDL-C, and TG levels to $120.8,48.5,68.5$, and $87.3 \mathrm{mg} / \mathrm{dL}$, respectively.

Our data showed that the probiotic-containing treatments (PFM and PPFM) were more efficient in lowering cholesterol than the phytosterol-containing treatment (PNFM). The PFM was the most efficient in reducing TC, followed by the PPFM, and then the PNFM (35.8, 24.2, and 21.6\%, respectively), whereas the PPFM was the most efficient in reducing LDL-C, followed by the PFM, and then the PNFM (41.7, 31.4, and $25.1 \%$, respectively). For TG, the PFM was also the most efficient, followed by the PPFM, and then the PNFM (28.5, 19.5, and $17.1 \%$, respectively). The ability of probiotics to reduce cholesterol is consistent with the findings of several previous studies (Usman and Hosono, 2000; Liong and Shah, 2006). Taranto et al. (2000) reported $38 \%$ TC reduction in mice fed $L b$. reuteri, and this result is comparable to ours. Also, Chiu et al. (2006) revealed the lowering effect of milk fermented with mixed Lactobacillus probiotic strains on TC, LDL-C, HDL-C, and TG levels of hypercholesterolemic hamsters. Lactobacilli lower serum cholesterol via different mechanisms, including direct cholesterol binding and assimilation in the intestine (Gilliland et al. 1985; Noh et al. 1997); deconjugation of bile acids, which induces cholesterol drainage to synthesize new bile acids (Liong and Shah, 2005); and inhibiting 3-hy-

Table 2. Serum and hepatic lipid profiles $(\mathrm{mg} / \mathrm{dL})$ of hypercholesterolemic rats fed probiotics and phytosterols alone or in combination ${ }^{1,2}$

\begin{tabular}{|c|c|c|c|c|c|c|}
\hline Item $^{3}$ & Control- & \multicolumn{4}{|c|}{ High-fat-high-cholesterol group (HFHC) } & $P$-value \\
\hline HDL-C & $58.2 \pm 4.5^{\mathrm{c}}$ & $85.1 \pm 4.2^{\mathrm{a}}$ & $48.6 \pm 2.1^{\mathrm{d}}$ & $68.2 \pm 4.1^{\mathrm{b}}$ & $68.5 \pm 3.1^{\mathrm{b}}$ & 0.0082 \\
\hline LDL-C & $54.6 \pm 2.3^{\mathrm{c}}$ & $83.2 \pm 4.8^{\mathrm{a}}$ & $57.1 \pm 2.8^{\mathrm{bc}}$ & $62.3 \pm 3.1^{\mathrm{b}}$ & $48.5 \pm 2.5^{\mathrm{d}}$ & 0.0085 \\
\hline $\mathrm{TG}$ & $77.5 \pm 4.5^{\mathrm{c}}$ & $110.8 \pm 5.4^{\mathrm{a}}$ & $79.2 \pm 5.5^{c}$ & $93.4 \pm 4.1^{\mathrm{b}}$ & $87.3 \pm 3.2^{\mathrm{b}}$ & 0.0091 \\
\hline TG & $15.7 \pm 1.0^{\mathrm{d}}$ & $199.3 \pm 12.5^{\mathrm{a}}$ & $28.1 \pm 1.9^{\mathrm{c}}$ & $16.1 \pm 0.9^{\mathrm{d}}$ & $39.7 \pm 2.3^{\mathrm{b}}$ & 0.0054 \\
\hline
\end{tabular}

\footnotetext{
${ }^{\mathrm{a}-\mathrm{d}}$ Means within the same row with different superscript letters are significantly different $(P<0.01)$.

${ }^{1}$ Control $-=$ group fed rodent chow; Control $+=$ group fed the HFHC diet and sterile skim milk (SSM); PFM = group fed probiotic-fermented milk; PNFM = group fed phytosterol-nonfermented milk; PPFM = group fed phytosterol-probiotic-fermented milk $\left(10^{10-11} \mathrm{cfu}\right.$ of probiotics and $25 \mathrm{mg}$ of phytosterols/rat per day).

${ }^{2}$ All values are means $\pm \operatorname{SEM}(\mathrm{n}=12)$.

${ }^{3} \mathrm{TC}=$ total cholesterol; HDL-C = high-density-lipoprotein cholesterol; LDL-C = low-density-lipoprotein cholesterol; TG = triglycerides.
} 
droxy-3-methyl-glutaryl (HMG)-CoA reductase enzyme (Fukushima and Nakano, 1996). The use of a cocktail of probiotics could mean that this cocktail possessed more than one of these mechanisms, and this could partly explain the higher cholesterol-lowering ability of probiotic cocktails over phytosterols. Comparable to our data, it was showed that phytosterol esters $(2 \mathrm{~g} / \mathrm{d})$ were able to lower LDL-C by 10 to $15 \%$ compared with $17.1 \%$ by the PNFM treatment (Moghadasian and Frohlich, 1999; Piironen et al., 2000). The ability of phytosterols to lower serum TC is due to their chemical structures, which are similar to cholesterol, so they can displace cholesterol from bile salt micelles and compete for absorption in the brush border, thus suppressing the absorption of dietary and biliary cholesterol (Ntanios and Jones, 1999). Moreover, our data showed that the symbiotic mixture (PPFM) was more efficient than the PFM in reducing LDL-C, and more efficient than the PNFM in reducing TC. Consistent with our findings, Chien et al. (2010) found that phytosterol-containing probiotic-fermented milk powder was more efficient in reducing serum TC, TG, LDL-C, and HDL-C than phytosterols alone. As well, Ho et al. (2007) showed that feeding $0.72 \%$ phytosterol-containing milk powder lowered $31 \%$ TC and $52 \%$ LDL-C of hypercholesterolemic hamsters. This symbiotic great ability could be due to the combined effect of the different cholesterol-lowering mechanisms possessed by the probiotic cocktails and phytosterols. However, our findings demonstrated that all the treatments used beneficially lowered serum TC, LDL-C, and TG, indicating the possibility of using these ingredients as useful dietary supplements in lowering cholesterol levels.

\section{Hepatic Total Cholesterol and Triglycerides}

Supplementation of the PFM, PNFM, and PPFM significantly $(P<0.01)$ reduced hepatic TC and TG levels compared with the CON+ group (Table 2). Our findings were consistent with those of Chien et al. (2010), who reported reductions in hepatic TC and TG of rats fed an HFHC diet with lactic-fermented milk powder containing $1.85 \%$ phytosterols for 4 wk. Moreover, Lin et al. (2004) reported that $0.24 \%$ phytosterol esters decreased hepatic cholesterol concentration by $44.3 \%$ in hamsters that were fed high-fat diets for 5 wk. The great reduction in hepatic TC and TG of the treated groups proved that serum TC was lowered and not redistributed between the blood and liver.

\section{Serum Thyroid Hormones and TSH}

Table 3 shows the effect of different treatments on serum TH and TSH levels of hypercholesterolemic rats. No significant differences were observed between the $\mathrm{CON}-$ and $\mathrm{CON}+$ groups for TH and TSH. Also, all the given treatments showed no significant effect on TSH levels. Whereas the PNFM and PPFM treatments significantly raised total T4 (T-T4) levels, no effect was observed by the PFM compared with the control groups. No effect on free T4 levels was shown by the PFM and PNFM, whereas the free T4 level was significantly reduced by the PPFM. Total T3 levels were significantly raised by the PNFM, PFM, and PPFM. Variable results were obtained for free triiodothyronine (fT3) by different treatments. Whereas the PPFM significantly raised the fT3 level, the PFM and PNFM significantly reduced it.

To our best knowledge, TH modulation effects of probiotics and phytosterols have been very scarcely studied and the literature on this topic is very limited. However, our results showed that the phytosterolcontaining treatments (PNFM and PPFM) seemed to induce a hyperthyroidism state in rats via elevation of the levels of T-T4, total T3 and fT3, and this effect may be suggested as a new additional mechanism of

Table 3. Plasma thyroid-stimulating hormones (TSH) and thyroid hormones of hypercholesterolemic rats fed probiotics and phytosterols alone or in combination ${ }^{1,2}$

High-fat-high-cholesterol group (HFHC)

\begin{tabular}{|c|c|c|c|c|c|c|}
\hline \multirow[b]{2}{*}{ Hormone $^{3}$} & \multirow[b]{2}{*}{ Control- } & & \multirow[b]{2}{*}{$P$-value } \\
\hline & & Control+ & PFM & PNFM & PPFM & \\
\hline $\mathrm{T}-\mathrm{T} 4(\mu \mathrm{g} / \mathrm{dL})$ & $1.940 \pm 0.100^{c}$ & $1.960 \pm 0.080^{\mathrm{c}}$ & $1.930 \pm 0.090^{\mathrm{c}}$ & $2.660 \pm 0.120^{\mathrm{a}}$ & $2.190 \pm 0.110^{\mathrm{b}}$ & 0.045 \\
\hline fT3 (pg/mL) & $1.420 \pm 0.040^{\mathrm{b}}$ & $1.460 \pm 0.050^{\mathrm{b}}$ & $1.330 \pm 0.030^{\mathrm{c}}$ & $1.230 \pm 0.060^{\mathrm{d}}$ & $2.140 \pm 0.100^{\mathrm{a}}$ & 0.044 \\
\hline
\end{tabular}

\footnotetext{
${ }^{\mathrm{a}-\mathrm{d}}$ Means within the same row followed by different superscript letters are significantly different $(P<0.05)$.

${ }^{1}$ Control $-=$ group fed rodent chow; Control $+=$ group fed the HFHC diet and sterile skim milk (SSM); PFM = group fed probiotic-fermented milk; PNFM = group fed phytosterol-nonfermented milk; PPFM = group fed phytosterol-probiotic-fermented milk $\left(10^{10-11} \mathrm{cfu}\right.$ of probiotics and $25 \mathrm{mg}$ of phytosterols/rat per day).

${ }^{2}$ All values are means $\pm \operatorname{SEM}(\mathrm{n}=12)$.

${ }^{3} \mathrm{~T}-\mathrm{T} 4=$ total thyroxine; fT4 $=$ free $\mathrm{T} 4$; $\mathrm{T}-\mathrm{T} 3=$ total triiodothyronine; $\mathrm{fT} 3=$ total $\mathrm{T} 3$.
} 
phytosterols to lower cholesterol, as the hyperthyroidism state has been shown to lower cholesterol. Panda et al. (2009) reported that administration of soy sterols (at $5.0 \mathrm{mg} / \mathrm{kg}$ for $21 \mathrm{~d}$ ) to mice significantly raised serum thyroxin and potentially induced hyperthyroidism. However, the PFM seemed not to induce hyperthyroidism, as it slightly elevated total T3, and this result is partly in agreement with those of Ali et al. (2004), who investigated the effect of probiotics on $\mathrm{TH}$ and reported that probiotics did not affect TH levels. Many studies, including ours, indicated that $\mathrm{TH}$ modulation could beneficially alter serum cholesterol (Forsythe, 1986, 1995; Potter, 1995). The hypocholesterolemic effect of some dietary ingredients, such as soy isolates and soy isoflavones, is believed to be partly due to modulating serum TH (Forsythe, 1986, 1995; Scholz-Ahrens et al., 1990). Huang et al. (2005) showed that soy protein isolates elevated TH levels (fT3 and T-T4), and this elevation could contribute to the lipid-lowering effect of soy protein. Moreover, inducing a hyperthyroidism state in human and rats by the administration of $\mathrm{T} 4$ lowered the LDL-C levels, and this was primarily due to the increased LDL-C receptor expression and, consequently, LDL-C clearance from serum (Lagor and Millar, 2010).

\section{CONCLUSIONS}

The present study demonstrated that a cocktail of probiotics, phytosterol mixtures, and their symbiotic combination beneficially lowered serum and hepatic cholesterol and TG, indicating the possibility of reducing CVD risk. Further investigations are recommended to ascertain the mode of action of these supplements in relation to THs modulation.

\section{REFERENCES}

Abd El-Salam, M. H., A. R. Hippen, F. M. Assem, K. El-Shafei, N. F. Tawfik, and M. El-Aassar. 2011. Preparation and properties of probiotic cheese high in conjugated linoleic acid content. Int. J. Dairy Technol. 64:64-74.

Ali, A. A., M. Velasquez, C. Hansen, and A. T. Mohamed. 2004. Effects of soybean isoflavones, probiotics, and their interactions on lipid metabolism and endocrine system in an animal model of obesity and diabetes. J. Nutr. Biochem. 15:583-590.

Awaisheh, S. S. 2011. Development of probiotic soft cheese manufactured using goat's milk with the addition of thyme. Milchwissenschaft 66:51-54.

Awaisheh, S. S., H. Al-Dmoor, S. Omar, A. Hawari, and M. Alroyli. 2012. Impact of selected nutraceuticals on viability of probiotic strains in milk during refrigerated storage at $4^{\circ} \mathrm{C}$ for 15 days. Int. J. Dairy Technol. 65:268-273.

Awaisheh, S. S., M. S. Y. Haddadin, and R. K. Robinson. 2005. Incorporation of selected nutraceuticals and probiotic bacteria into a fermented milk. Int. Dairy J. 15:1184-1190.

Brashears, M. M., S. E. Gilliland, and L. M. Buck. 1998. Bile salt deconjugation and cholesterol removal from media by Lactobacillus casei. J. Dairy Sci. 81:2103-2110.
Chien, Y. L., L. Y. Wu, T. C. Lee, and L. S. Hwang. 2010. Cholesterol-lowering effect of phytosterol-containing lactic-fermented milk powder in hamsters. Food Chem. 119:1121-1126.

Chiu, C.-H., T.-Y. Lu, Y.-Y. Tseng, and T.-M. Pan. 2006. The effects of Lactobacillus-fermented milk on lipid metabolism in hamsters fed on high-cholesterol diet. Appl. Microbiol. Biotechnol. 71:238-245.

Danneman, P. J., S. Stein, and S. O. Walshaw. 1997. Humane and practical implications of using carbon dioxide mixed with oxygen for anesthesia or euthanasia of rats. Lab. Anim. Sci. 47:376-385.

Folch, J., M. Lees, and G. H. Sloane Stanley. 1957. A simple method for the isolation and purification of total lipid from animal tissue. J. Biol. Chem. 226:497-509.

Forsythe, W. A. 1986. Comparison of dietary casein or soy protein effects on plasma lipids and hormone concentrations in the gerbil (Meriones unguiculatus). J. Nutr. 116:1165-1171.

Forsythe, W. A. 1995. Soy protein, thyroid regulation and cholesterol metabolism. J. Nutr. 125:619S-623S.

Fukushima, M., and M. Nakano. 1996. Effects of mixture of organisms, Lactobacillus acidophilus or Streptococcus faecalis on cholesterol metabolism in rats fed on a fat- and cholesterol-enriched diet. $\mathrm{Br}$. J. Nutr. 76:857-867.

Gilliland, S. E., C. R. Nelson, and C. Maxwell. 1985. Assimilation of cholesterol by Lactobacillus acidophilus. Appl. Environ. Microbiol. 49:377-381.

Ho, C.-C., Y.-L. Chein, and L. S. Hwang. 2007. Beneficial effects of plant sterols/stanols-containing milk powder on lipid metabolism in hamsters. J. Food Drug Anal. 15:191-201.

Huang, W., C. Wood, M. R. L'Abbé, G. S. Gilani, K. A. Cockell, and C. W. Xiao. 2005. Soy protein isolate increases hepatic thyroid hormone receptor content and inhibits its binding to target genes in rats. J. Nutr. 135:1631-1635.

ILAR (Institute of Laboratory Animal Resources). 1996. Guide for the Care and Use of Laboratory Animals. ILAR, Washington, DC.

Kiortsis, D. N., T. D. Filippatos, D. P. Mikhailidis, M. S. Elisaf, and E. N. Liberopoulos. 2007. Statin-associated adverse effects beyond muscle and liver toxicity. Atherosclerosis 195:7-16.

Lagor, W. R., and J. S. Millar. 2010. Overview of the LDL-C receptor: Relevance to cholesterol metabolism and future approaches for the treatment of coronary heart disease. J. Receptor Ligand Channel Res. 3:1-14.

Lin, Y., G. W. Meijer, M. A. Vermeer, and E. A. Trautwein. 2004. Soy protein enhances the cholesterol-lowering effect of plant sterol esters in cholesterol-fed hamsters. J. Nutr. 134:143-148.

Liong, M. T., and N. P. Shah. 2005. Bile salt deconjugation ability, bile salt hydrolase activity and cholesterol co-precipitation ability of lactobacilli strains. Int. Dairy J. 15:391-398.

Liong, M. T., and N. P. Shah. 2006. Effects of a Lactobacillus casei synbiotic on serum lipoprotein, intestinal microflora, and organic acids in rats. J. Dairy Sci. 89:1390-1399.

Mannarino, E., M. Pirro, C. Cortese, G. Lupattelli, D. Siepi, A. Mezzetti, S. Bertolini, M. Parillo, R. Fellin, A. Pujia, M. Averna, C. Nicolle, and A. Notarbartolo. 2009. Effects of a phytosterol-enriched dairy product on lipids, sterols and 8-isoprostane in hypercholesterolemic patients: A multicenter Italian study. Nutr. Metab. Cardiovasc. Dis. 19:84-90.

Moghadasian, M. H., and J. J. Frohlich. 1999. Effects of dietary phytosterols on cholesterol metabolism and atherosclerosis: Clinical and experimental evidence. Am. J. Med. 107:588-594.

Noh, D. O., S. H. Kim, and S. E. Gilliland. 1997. Incorporation of cholesterol into the cellular membrane of Lactobacillus acidophilus ATCC 43121. J. Dairy Sci. 80:3107-3113.

Ntanios, F. Y., and P. J. H. Jones. 1999. Dietary sitostanol reciprocally influences cholesterol absorption and biosynthesis in hamsters and rabbits. Atherosclerosis 143:341-351.

Panda, S., A. Kar, and S. Patil. 2009. Soy sterols in regulation of thyroid functions, glucose homeostasis, and hepatic peroxidation in mice. Food Res. Int. 42:1087-1092.

Piironen, V., D. G. Lindsay, T. A. Miettinen, J. Toivo, and A. M. Lampi. 2000. Plant sterols: Biosynthesis, biological function and 
their importance to human nutrition. J. Sci. Food Agric. 80:939966.

Potter, S. M. 1995. Overview of proposed mechanisms for the hypocholesterolemic effect of soy. J. Nutr. 125:606S-611S.

Reeves, P. G., F. H. Nielsen, and G. C. Fahey Jr. 1993. AIN-93 purified diets for laboratory rodents: Final report of the American Institute of Nutrition ad hoc writing committee on the reformulation of the AIN-76A rodent diets. J. Nutr. 123:1939-1951.

Scholz-Ahrens, K. A., H. Hagemeister, J. Unshelm, N. Agergaard, and C. A. Barth. 1990. Response of hormones modulating plasma cholesterol to dietary casein or soy protein in mini pigs. J. Nutr. 120:1387-1392.

Schrezenmeir, J., and M. de Vrese. 2001. Probiotics, prebiotics, and synbiotics-Approaching a definition. Am. J. Clin. Nutr. 73:361S-364S

Shin, D. J., and T. F. Osborne. 2003. Thyroid hormone regulation and cholesterol metabolism are connected through sterol regulatory element-binding protein-2 (SREBP-2). J. Biol. Chem. 278:3411434118.
SAS Institute. 2011. SAS software version 9.3. SAS Institute Inc., Cary, NC

Sibel Akalin, A., Siddik Gönç, and Selmin Düzel. 1997. Influence of yogurt and acidophilus yogurt on serum cholesterol levels in mice. J. Dairy Sci. 80:2721-2725.

Talbert, R. L. 2006. Safety issues with statin therapy. J. Am. Pharm. Assoc. 46:479-490.

Taranto, M. P., M. Medici, G. Perdigon, A. P. Holgado, and G. F. Valdez. 2000. Effect of Lactobacillus reuteri on the prevention of hypercholesterolemia in mice. J. Dairy Sci. 83:401-403.

Usman, and A. Hosono. 2000. Effect of administration of Lactobacillus gasseri on serum lipids and fecal steroids in hypercholesterolemic rats. J. Dairy Sci. 83:1705-1711.

WHO (World Health Organization). 2007. Prevention of cardiovascular disease: Guidelines for assessment and management of cardiovascular risk. WHO, Geneva, Switzerland. 